\title{
TECHNOLOGY STOCKS AND ECONOMIC PERFORMANCE OF GOVERNMENT-LINKED COMPANIES: THE CASE OF MALAYSIA
}

\author{
Chan-Yuan Wong' , V. G. R. Chandran Govindaraju ${ }^{2}$ \\ ${ }^{1}$ Department of Science and Technology Studies, University of Malaya, 50610 Kuala Lumpur, Malaysia \\ ${ }^{2}$ Department of Economics, University of Malaya, 50610 Kuala Lumpur, Malaysia \\ E-mails: ${ }^{1}$ wongcy111@gmail.com; ${ }^{2}$ vgrchan@gmail.com (corresponding author)
}

Received 5 October 2010; accepted 9 June 2011

\begin{abstract}
On the basis of the case study of the selected government-linked companies (GLCs), this paper examines the technological stock progress and further assesses its implication for growth. A synthesized framework of analysis (using technological stock and logistic growth function) is proposed to highlight the virtuous cycle between R\&D investment, technology stock and growth. The results suggest that two of the selected firms (Proton and Golden Hope), indeed, showed better technological progress. However, Proton seems to achieve the maturity stage of technology and further needs to enhance its technology capability to drive its performance in the future. In contrast, TNB is found to lack the technological development to promote performance. The results, on the one hand, suggest that technology development is mostly progressive with high returns in the areas where the country has definite comparative advantage (e.g. oil palm) and when better partnership exists. On the other hand, in a highly protective market, the technological progress is slow - the case of energy sector - and contribution of technology progress towards growth is in lack - as in the case of automotive sector. Case comparison suggests that attempts to develop technology require competitive market with less government protective measures.
\end{abstract}

Keywords: technology stock, government-linked companies, economic performance, Malaysia.

Reference to this paper should be made as follows: Wong, C.-Y.; Govindaraju, V. G. R. C. 2012. Technology stocks and economic performance of government-linked companies: the case of Malaysia, Technological and Economic Development of Economy 18(2): 248-261.

JEL Classification: O32, C50, L16.

\section{Introduction}

The renewed interest in political economy in the forms of institutional role (North 1990; Nelson 2005) that shapes the firm's conduct and performance is an emerging field in the current trends of economy analysis (Adam, Dercon 2009). In East Asia, Johnson (1982) highlighted 
the importance of government intervention policies in assessing the economic development. In many Asian countries, government intervention is more than just institutional setting that facilitates industrial development. The dual role of the government, controlling state (control and regulate private sectors) as well as producing state (directly producing by enacting suitable economic policies), is imperative for economic performance of these countries. In China, Singapore and Malaysia, for instance, government actively played the producing state role. Government sets up group of government-linked companies (GLCs) or state owned enterprises (SOE) and actively charts economic development in the respective economy (Nolan, Xiaoqiang 1999; Feng et al. 2004; Ang, Ding 2006; Lin, Su 2009). In the era of globalization, improving the competiveness of the GLCs is important for future growth of these nations due to the heavy reliance of state producing approach. In specific, improving the most important source of competitiveness, technological progress, is crucial for the progress of GLCs (Girma et al. 2009) and indirectly for the nation as a whole.

As a result, action to improve technology and innovation activities of GLCs, if sustained, should help improve the overall industrial competitiveness in Malaysia. However, proponents of market economics argued on the superiority of privately owned firms over government owned (Shleifer 1998; Dewenter, Malatesta 2001). Ownership has been a central point of investigation for economic performance in this aspect (Molas-Gallart, Tang 2006; Love et al. 2009; Moreno, Castillo 2011). In Asia, there is mixed evidence how government or state owned enterprise perform. In the case of Singapore, studies reached consensus that GLCs are more efficient than the non-GLCs (Feng et al. 2004; Ang, Ding 2006). Likewise, in China most of the studies recognized the growing ability of SOEs. This is attributed to the economic reform policies. Nolan and Xiaoqiang (1999) argued that greater enterprise autonomy, the impact of market forces, global integration, growth of domestic demand and the government's effort to promote large enterprise as the key factors contributing to the competitiveness of SOEs. Nevertheless, despite their better performance, Kong et al. (1999) and Zheng et al. (2003) showed that technological development of SOEs are still poor. In contrast, in the case of India, there is mixed evidence. For instance, Majumdar (1995) found the state owned sector less efficient compared to its private sector counterparts, while Dholakia (1987) is of the opinion that overall total factor productivity of state owned enterprise is far better than private firms. While these studies have made significant contributions, some important issues remained to be addressed. First, to the best of our knowledge, there has been a lack of empirical evidence assessing the technology progress and its growth implications for the GLCs. To date, except the study by Zheng et al. (2003) and Kong et al. (1999) in China, other studies only compared and focused on financial performance measures of GLCs and non-GLCs. Secondly, studies assessing the progress of GLCs in Malaysia are limited except the assessment from the political economic perspective (see Gomez 2009).

This paper attempts to fill the fundamental research gaps in development economies on the performance of GLCs with regards to research and development capabilities. This paper addresses simple but fundamental question: do GLCs learn and develop technology capabilities over time? In doing so, the paper attempts to trace the development trajectories based on logistic growth function considering technology stock and economic growth in three most government owned performing firms in R\&D; Perusahaan Otomobil National (Proton), 
Tenaga Nasional Bhd (TNB) and Golden Hope Plantations. Commitments and initiatives to improve competitiveness appear to be in place in these selected firms; however, it remains to be observed to what degree of success is their technological development. By means of theoretical analysis and empirical demonstration, this study aims to provide an integrated picture of changing nature of technology in the selected firms.

The rest of the paper is organized as follows. Section 2 describes briefly the economic development and GLCs participation in the Malaysian economy. Section 3 provides the background information of the selected companies. A practical empirical method, employing technological stocks function and logistic growth function to elucidate the potential of the development will be proposed and presented in Section 4. Section 5 presents the empirical results to showcase the development trajectories of the selected firms. Finally, section 6 provides the conclusion, policy implications, limitations and future research directions.

\section{Economics development and GLCs in Malaysia}

Development policies in Malaysia had experienced a significant change since the introduction of development plans in the 1960s. Rasiah $(1995,2001,2002)$ elucidated the changes over 1960 s to 1990s of the industrial economic structure, progress from an economy dependent on agriculture and primary commodities to a manufacturing based and export driven economy. The economic development in Malaysia is influence by two different development models, namely neo-liberalism policies and the development state model (Gomez 2009). On the one hand, government's subscription to neo-liberal policies contributes to the economic liberalization, privatization as well as increases the foreign participation in the economy. On the other hand, under the administration of former prime minister, Mahathir Mohammad, the developmental state model supports the domestic industries and the development of large conglomerates based on South Korean chaebols and Japanese zaibatsu (Gomez 2009). In tandem with this, the developmental model was also influenced by New Economy Policy (NEP) that was first announced in 1970 to eradicate poverty and restructured the economy to address the imbalances of capital income between ethnical groups. This has directly increased the state participation in the corporate sector and the creation of government-linked companies. Since then, GLCs are given certain privileges, priority for government contracts, and incentives and supports, over other firms existing in Malaysia. As of March 2007, market capitalization of the 20 listed GLCs companies is RM 228 billion, an increase from 145 billion in May 2004. Although GLCs only account around 5\% of the firms listed in Bursa Malaysia, GLCs market capitalization is about $36 \%$ of the total market capitalization and $54 \%$ of the benchmark Kuala Lumpur Composite Index. In addition, the government aims to promote GLCs to advance the economic development in Malaysia. GLCs are primarily used as the catalyst of the government's efforts under the New Economic Model that emphasize on technological development capabilities and innovation that will eventually drive Malaysia into higher income nation. The government launched the GLC transformation program in May 2004 to further strengthen the GLCs to become high-performing entities. The Putrajaya Committee on GLC High Performance (PCG) was setup up to design and implement national policies to transform GLC to become high-performing entities as well as to establish 
institutional framework to execute programs, policies and guidelines. And, to improve the development of GLCs, ten initiatives namely improving board effectiveness, strengthening directors' capabilities, upgrading monitoring and management functions, improving regulatory environment, clarifying social obligations, reviewing and revamping procurement practices, optimizing capital management practices, improving human capital, enhancing performance management practices as well as operational practices were identified. The transformation is aimed to catalyst the Malaysian economic development.

However, there has been much criticism over the GLCs, especially due to the poor performance of key companies such as Proton and Malaysia Airlines. Additionally, it has been argued that the distorted market processes due to the state intervention has led to unproductive, corrupt and wasteful activities in Malaysian market (Alavi 1999). In addition, the growth of R\&D activities has not been promising in most GLCs, despite laudable government efforts in upgrading the infrastructures to develop their technology. Firstly, the R\&D investment is still low except for Proton and secondly the returns of R\&D are still poor (see Table 1). It is widely believed that state intervention practice is essential to build technology capabilities and competencies (Nelson 1993; Alavi 1999; Reinert 2008), particularly during the infant stage of industrial development. The government incentives and supports may fuel entrepreneurial activities, reduced risks by firms that are involved in costly investment for innovation, and stimulates R\&D investment for science and technology. However, assessment on such issues especially in the government owned organizations is a lack. Therefore, a key issue here, one with important policy ramifications, is to examine the technological progress of GLCs and their likely returns to sustaining growth.

Table 1. R\&D investment in selected GLCs, 1997-2004

\begin{tabular}{llccc}
\hline \multirow{2}{*}{ Company } & \multicolumn{1}{c}{ Sector } & \multicolumn{3}{c}{ R\&D/Sales (\%) } \\
\cline { 3 - 5 } & & 1997 & 2000 & 2004 \\
\hline Proton & Automobile & 1.79 & 2.91 & 3.62 \\
Telekom & Telecommunication & - & - & 0.25 \\
Tenaga Nasional Bhd & Energy & 0.31 & 0.12 & 0.10 \\
Golden Hope & Plantation & 0.08 & 0.20 & 0.63 \\
Guthrie & Plantation & - & 0.71 & 0.71 \\
\hline
\end{tabular}

Source: Chhabra 2007

\section{Concept and proposed synthesized framework of analysis}

This section discusses the methodology of the study and explains technological stock and logistic growth function useful for examining technological progress and their likely returns to sustainable growth. We first focus on the concept of technological stock useful for modeling the accumulation of the technology of firm in correlation with growth. Logistic growth function theory for this study is discussed in the following sub-section. This followed by discussion on how to examine a likely sustainable growth of the selected firms using logistic growth theory. 


\subsection{Technological stock}

Firms' innovative capability is highly dependent on previous technological stock and R\&D investment for new technology (Hu, Tseng 2007). These sources, recognized as institutional dynamics, are essential for the progress of science and technology. In order to assess in detail the systemic mechanism that induces technology vitality in the selected firms, the technological stock function is examined. Malerba et al. (1997) and Han (2007) showed that the production of new technology is strongly dependent on the accumulation of technological stock due to the path-dependent nature. The analysis of this nature provides a coherent phenomenon of the development of technology. Following Tarasyev and Watanabe (1999), technological stock (TS) can be expressed as follows:

$$
T S_{t}=T_{(t)}+(1-\sigma) T_{(t-1)} .
$$

Technological stock is dependent on the stock in the previous year with the effect of $13 \%$ obsolescence rate $(\sigma)$ and the knowledge input $\left(T_{(t)}\right)$, which is proxied by R\&D input in year $t$. The obsolescence rate is estimated by Parkes and Schankerman (1984), and used for most industries in the studies by Park, G. and Park, Y. (2006) and Han (2007). The following function expresses the sum of technology stock from the base year $(b)$ to $(t)$ :

$$
T S_{t}=T_{(t)}+(1-\sigma) T_{(t-1)}+(1-\sigma)\left(1-\sigma_{t-1}\right) T_{(t-2)}+\ldots+(1-\sigma) . .\left(1-\sigma_{(t-b)}\right) T_{(b)} .
$$

Once the technology stock is estimated, the correlation plot between sales (value fixed at 2000) and estimated technology stock of a firm would explain the capacity to assimilate and utilize the accumulated knowledge for growth and production. This relationship is presented in graphical forms to explain the correlation between TS and growth in the selected GLCs.

\subsection{S-curve growth, logistic growth function and multifactor productivity}

It is common that technological development characteristic shows an 'S-curve' growth pattern (Rogers 1995; Wong et al. 2010). Twiss (1992) and Rogers (1995) highlighted that the S-curve can be considered as consisting of three stages: incubation, rapid growth and maturity length. As shown in Figure 1, the incubation period that is characterized by slow growth in sales over stock of technology is lengthy, implied mismatch of technology with the market demand. Once the technology is gradually accepted as providing high economic value of products/processes to the market, the growth of sales raises rapidly until it approaches the carrying capacity (see Rogers 1995: 38-105). In order to sustain the growth of sales over time, it is indispensable for firms to develop new technological avenue to substitute the existing technology in contributing to the growth of sales.

Modeling technological growth along the S-curve can be appropriated by fitting data from its emergence to the present development and extrapolated into future growth or saturation to a limiting level. This process is much alike to the infection process of an epidemic disease and these processes are characterized by S-curved growth pattern (Rogers 1995). In this study, we attempt to model the technology by fitting suitable growth functions that can explain the development process adequately. The logistic function illustrated in equation (3) is of the most common form. This logistic growth function that originates in the biological 
realm ${ }^{1}$ is often used to model the growth of technology (See Fig. 1). This is mainly due to its rich empirical description and its devices are found effective in capturing the changing nature of technologies (Devezas et al. 2005; Bengisu, Nekhili 2005; Wong, Goh 2010a, b).

$$
p_{t}=\frac{K}{1+a e^{-b t}}
$$

where $p=$ value of the technological parameter; $t=$ time; $K=$ carrying capacity $a$ and $b$ are coefficients of carrying capacity and time respectively.

To plot the S-curve on log-linear model,

$$
\begin{aligned}
& K=p_{t}\left(1+a e^{-b t}\right), \\
& \frac{K}{p_{t}}-1=a e^{-b t}, \\
& \log \left(\frac{K}{p_{t}}-1\right)=\log a+b t .
\end{aligned}
$$

The natural limit of development (carrying capacity) is estimated through the data linearization technique (Mathews 1992). Fitting the logistic curve to data is presented through judicious selection of $K^{2}$.

The velocity $v_{t}$ of the development of $p$ is given by:

$$
\frac{d p_{t}}{d t}=b p_{t} \cdot\left(1-\frac{p_{t}}{K}\right)
$$

The coefficient $b$ measures the initial velocity of the growth curve (Zhu et al. 2002), as $b \rightarrow v_{t}$ when $p_{t} \rightarrow 0$. The logistic growth function as given in Equation (3) is used to examine the growth trajectory of the selected Malaysian GLCs. Annual R\&D investment and sales data were used to measure stock and its marginal factor productivity. The data covers 1997 to 2005 and were obtained from the respective firms' annual report. The selection of firms was based on data availability.

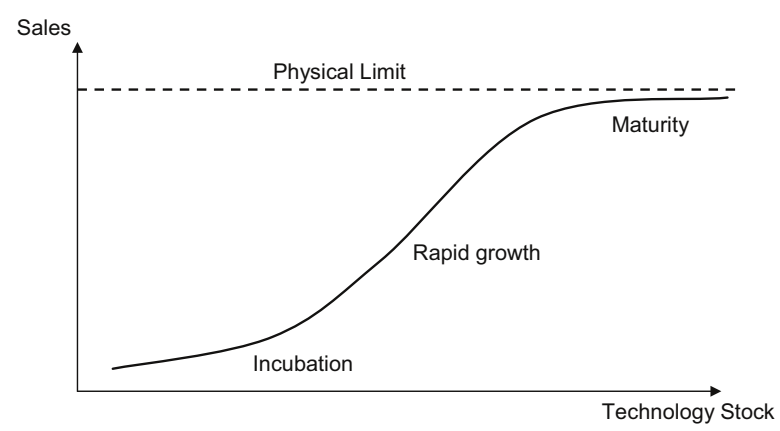

Fig. 1. The S-curve of technology progress

\footnotetext{
The function is also commonly used to study population growth, a metaphor of biological realm such as evolution, selection, life cycle and survival of the fittest.

2 A value that is selected through least square line and useful for calculating the coefficients of $a$ and $b$.
} 
The estimation using logistic growth function is useful to highlight the virtuous cycle between R\&D investment, technology stock and growth of the selected firms. Constructing a virtuous cycle between R\&D investment, stock of technology and economic growth is essential for firms to remain at the apex of welfare in knowledge-based economic system. Figure 2 implies that increases in research investment $(R)$ contribute to increases in technology stocks $(T)$, in which marginal productivity of technology $(M P T)$ will accelerate.

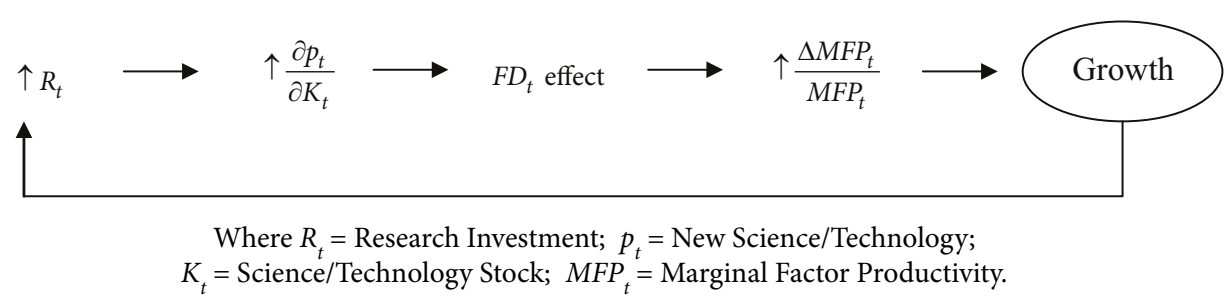

Fig. 2. Virtuous cycle leading to increase of science/ technology stock and multifactor productivity. Source: Adapted from Watanabe et al. (2006)

$M P T$ suggests the ability to improve performance of production processes, goods and services, termed as functionality development (FD) (Watanabe et al. 2003). The increase of $M P T$ will induce multifactor of productivity (MFP). MFP denotes to the constant in CobbDouglas production function, the variable in which accounts for economic growth not caused by the input variable in output (Watanabe et al. 2006).

Building upon Solow's model of production function (see Romer 1996), $\frac{\triangle M F P}{M F P}$ can be depicted as $\frac{\partial p_{t}}{\partial T_{t}} \frac{R_{t}}{p_{t}}$, where $\frac{\partial p_{t}}{\partial T_{t}}$ is MPT. Given $F D_{t}$ is $\frac{K}{p_{t}}, \frac{\partial p_{t}}{\partial T_{t}}$ is depicted as $b p_{t}\left(1-\frac{1}{F D_{t}}\right)$ (see Watanabe et al. 2006). Therefore, change rate of multifactor productivity at time $t$ can be measured as $\left(\frac{\Delta M F P}{M F P}\right)_{t}=M P T \frac{R_{t}}{p_{t}}$.

\section{Results and discussion}

Firstly, we discussed the results of the technological stock of the selected GLCs obtained from the fitted models and how they correlated with firm performance. Figure 3 presents some basic data on selected firms' growth and trends in sales and technological stock. The results show that Proton and Golden Hope recorded significant growth in sale and witness a parallel take-off with technological stock. This reflects the fact that the commitment in R\&D of Proton and Golden Hope is likely to develop technological capabilities to capture a significant share of capital market. Particularly, the trend of Golden Hope is linear and accelerating, exhibiting remarkable technological development and commitments in catching up with the frontiers. With oil palm technology being in the frontier in Malaysia, this industry has also benefited from the assistance of Palm Oil Research Institute of Malaysia (PORIM) and the Malaysian Palm Oil Board. The synergy has largely contributed to the technology development. For instance, Golden Hope is involved in the production of biodiesel with the 

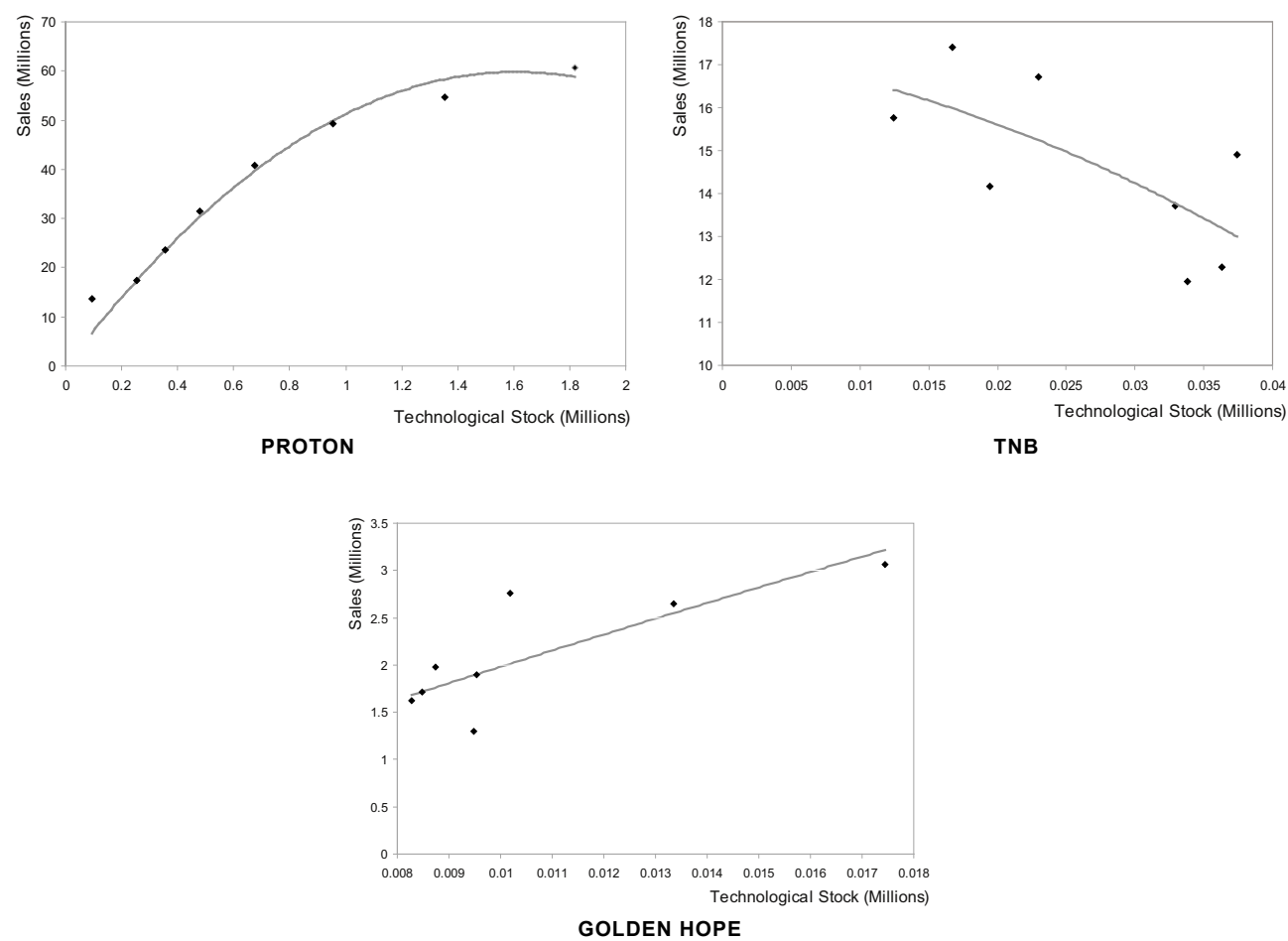

Fig. 3. Technological trajectory of Malaysian GLCs

use of MPOB's technology. Indeed, joint venture and collaboration with global players like Cognis Deutschland GmbH \& Co. KG of Germany and Sumitomo of Japan provided the needed means for technology transfer and know-how. As a whole, Golden Hope research centre has benefited through the government support that targeted to develop the oil palm industries as well as strategic partnership with global players.

On the other hand, the trend of Proton signifies that the development is entering the border of its maturity stage, rendering the state of diminishing return to scale. Proton holds on to the old technological paradigm ${ }^{3}$, creating a barrier in turning into a new paradigm (building indigenous technology). While relying only on the domestic market and with a lack of ability to penetrate the export markets, the limited economies of scale may not be able to push Proton to the next technology frontier or even undertake significant R\&D without the government support. The gap between the global auto player and Proton remains large, in terms of energy efficient vehicles and ability to launch new models in a short time. Indeed, reliance on Japanese technology and management processes is still prevalent even after 23 years of establishment. To date, learning has been slow and protective government support is still needed. Proton requires drastic changes to make the accumulated knowledge obsolete in the current technological paradigm (Wad, Chandran 2011).

3 Technological innovations of Proton were built upon Mitsubishi's knowledge stock. 
For the case of TNB, technological stock records negative correlation with the growth of sales, suggesting insignificant impact of R\&D investment to growth in sales. The trend exhibits a rather rapid decline. This trend is in contrast to many studies which suggested that in high-tech sectors, particularly in energy sector, R\&D investment would lead to the growth in performance (see Watanabe et al. 2002). The trends appeared to be anomaly, suggesting the absence of technological learning in TNB over the years. This might be partly due to the active role played by independent power suppliers. TNB has to even reduce its producing capacity due to the over supply of electricity by the independent power suppliers. Due to the contract obligations TNB is a force to buy power from IPP. In addition, the active role played by the IPP might also reduce the technological progress of TNB let alone the profitability and sales.

The result of the growth trajectory of the GLCs is shown in Table 2. The growth function with a carrying capacity stated in Equation (3) is fitted to cumulative sales of the selected GLCs. The $t$-values shown in Table 2 indicate that the estimated parameters of the growth functions are statistically significant for all cases. The statistical significant substantiates the effectiveness of logistic growth function in capturing the growth behavior of sales for the selected GLCs.

Table 2. Results for the development of GLCs

\begin{tabular}{lcccccccccccc}
\hline & \multicolumn{3}{c}{ Fit statistics } & & \multicolumn{2}{c}{$F D$} & & $M P T$ & \multicolumn{2}{c}{$\frac{\Delta M F P_{t}}{M F P_{t}}$} \\
\cline { 2 - 13 } & $K$ & $a$ & $b$ & $\begin{array}{c}\text { Adj } \\
R^{2}\end{array}$ & 1998 & 2005 & 1998 & 2005 & 1998 & 2005 \\
& & & & & & & & & \\
\hline Proton & 340.70 & 61.65 & 0.64 & 0.99 & 33.51 & 1.37 & 6.31 & 42.91 & 0.300 & 4.126 \\
& $(3.83)$ & $(45.48)$ & $(35.64)$ & & & & & & & \\
\hline TNB & 180.70 & 9.39 & 0.39 & 0.99 & 7.31 & 1.42 & 8.25 & 14.61 & 0.026 & 0.027 \\
& $(4.85)$ & $(49.12)$ & $(43.09)$ & & & & & & & \\
\hline Golden Hope & 40.70 & 13.83 & 0.31 & 0.99 & 11.14 & 2.16 & 1.03 & 3.14 & 0.005 & 0.018 \\
& $(7.51)$ & $(40.76)$ & $(24.18)$ & & & & & & & \\
\hline
\end{tabular}

The FD, MPT and MFP change rate in 1996 and 2005, as reported in Table 2, generally suggest that the selected firms (excluding TNB) have succeeded in building technology capabilities over years. The firms witnessed significant growth in MPT and contributed to the increase in multifactor productivity of their production function. Thus, growth in sales is expected.

The growth of R\&D investment has not been promising in TNB, despite significant government efforts in upgrading the infrastructures to develop their technology capabilities. This may be attributed to poor monitoring tasks, enforcement and measures from the Malaysian government to ensure technological development in the firm. While Proton and Golden Hope benefit from their development of technology, it is noteworthy that their MFP change rates are entering the border of the maturity stages (see Fig. 4). Following this peak, the firms are likely to witness rapid decline if there is no progress in their technological system for new growth trajectories. 


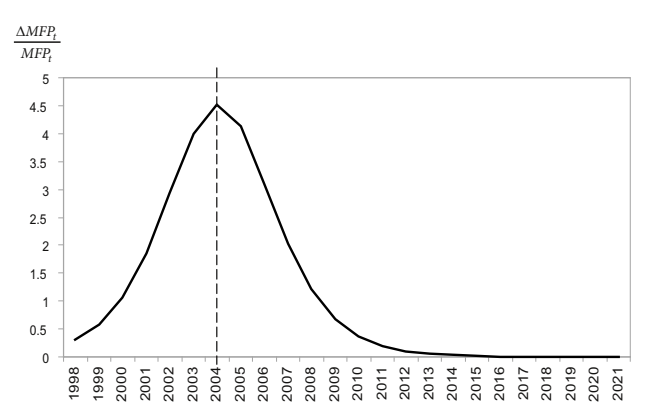

PROTON

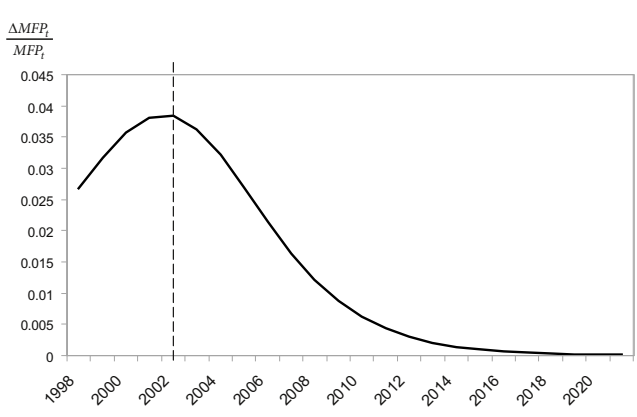

TNB

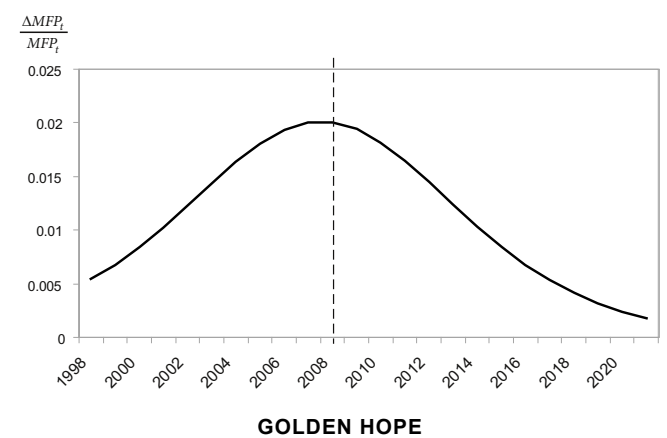

Fig. 4. MFP change rate in GLCs

\section{Conclusion}

In line with the analytical framework and analysis stated in the preceding section, attempting at analyzing the technology development of Malaysian GLCs, an extensive analysis to trace the development trajectories based on the logistic growth function has been conducted in this paper. The conceptual framework proposed in this study offers a quantitative approach to explore the technological development of GLCs. Malaysian GLCs play a significant role in Malaysian economic development; some of those have developed technological capabilities over the years. However, in our study of TNB no significant changes in technology are implied. The over-protection of Malaysian energy sector and its inefficient functioning market and poor monitoring tasks to ensure development may be the reasons for the lack of progress in technology. As a whole, it can be concluded that technology development is mostly progressive in the areas where the country has definite comparative advantage (e.g. oil palm) and when better partnership exists. While being under heavy protective market, in the case of automotive and energy sectors, lack of technological contribution to growth and less technological progress are evident, respectively. However, the results cannot provide a definitive case against infant industry protection by the state, as Golden Hope benefited from the assistance of state research institutions, PORIM and the Malaysian Palm Oil Board. The 
success of an economic development attributes to an array of institution and the role of the state as the manager of an institutional system. Therefore, a pragmatic approach ${ }^{4}$ from the state to develop firms' technological capabilities is vital for development.

Although the study provides useful insights on the technological progress at macro level, limitations of the study warrant some attention. In quantifying the technological progress and its relationship with performance, this paper only relies on a simplified production function that may not be able to capture many institutional changes that the selected firms had taken. Therefore, the results obtained from this function have been interpreted with caution for meaningful implications. This study also qualifies that the statistics on R\&D may not be the perfect indicator of technological stock. Many technological activities of GLCs may not be captured by the R\&D investment, while this investment may not necessarily lead to technological development. For the lack of a better measure, this study adopted the common approach as in many literatures that use $\mathrm{R} \& \mathrm{D}$ investment as the measurement of technology stocks. It is noteworthy for future research to dwell into the issues of measurement.

\section{References}

Adam, C.; Dercon, S. 2009. The political economy of development: an assessment, Oxford Review of Economic Policy 25(2): 173-189. http://dx.doi.org/10.1093/oxrep/grp020

Alavi, R. 1999. Rents, technological innovation and firms competitiveness in a Bumiputera Malaysian firm, in Jomo, K. S., et al. (Ed.). Industrial Technological Development in Malaysia. London: Routledge.

Ang, J. S.; Ding, D. K. 2006. Government ownership and the performance of government linked companies: the case of Singapore, Journal of Multiple Financial Management 16(1): 64-88.

http://dx.doi.org/10.1016/j.mulfin.2005.04.010

Bengisu, M.; Nekhili, R. 2005. Forecasting emerging technologies with the aid of science and technology databases, Technological Forecasting and Social Change 73(7): 835-844.

http://dx.doi.org/10.1016/j.techfore.2005.09.001

Chhabra, E. 2007. A Critical Assessment of the Venture Capital Industry in Malaysia: Master's Thesis. Malaysia University of Science and Technology.

Devezas, T. C.; Linstone, H. A.; Santos, H. J. S. 2005. The growth dynamics of the internet and the long wave theory, Technological Forecasting and Social Change 72(8): 913-935. http://dx.doi.org/10.1016/j.techfore.2005.06.001

Dewenter, K.; Malatesta, P. H. 2001. State-owned and privately-owned firms: an empirical analysis of profitability, leverage, and labor intensity, American Economic Review 91(1): 320-334. http://dx.doi.org/10.1257/aer.91.1.320

Dholakia, B. H. 1987. Relative performance of public and private manufacturing enterprises in India: total factor productivity approach, Economic and Political Weekly February 25, 13: M4-11.

Feng, F.; Sun, Q.; Tong, W. H. S. 2004. Do government-linked companies underperform?, Journal of Banking and Finance 28(24): 2461-2492. http://dx.doi.org/10.1016/j.jbankfin.2003.10.012

Girma, S.; Gong, Y.; Gorg, H. 2009. What determines innovation activity in Chinese state-owned enterprises? The role of foreign direct investment, World Development 37(4): 866-873. http://dx.doi.org/10.1016/j.worlddev.2008.07.017

4 The state has to ensure that the firms are prudently managed and developing selective equity-based technology alliances with the customers. 
Gomez, E. T. 2009. The rise and fall of capital: corporate Malaysia in historical perspective, Journal of Contemporary Asia 39(3): 345-381. http://dx.doi.org/10.1080/00472330902944404

Han, Y.-J. 2007. Measuring industrial knowledge stocks with patents and papers, Journal of Informetrics 1(4): 269-279. http://dx.doi.org/10.1016/j.joi.2007.06.001

$\mathrm{Hu}, \mathrm{M}$. C.; Tseng, C. Y. 2007. Technological interdependence and knowledge diffusion in the building of national innovative capacity: the role of Taiwan's chemical industry, Technological Forecasting and Social Change 74(3): 298-312. http://dx.doi.org/10.1016/j.techfore.2006.04.001

Johnson, C. 1982. MITI and the Japanese Miracle: the Growth of Industrial Policy. Stanford: Stanford University Press, 1925-1975.

Kong, X.; Marks, R. E.; Wan, G. H. 1999. Technical efficiency, technological change and total factor productivity growth in Chinese state-owned enterprises in the early 1990s, Asian Economic Journal 13(3): 267-282. http://dx.doi.org/10.1111/1467-8381.00085

Lin, C.; Su, D. 2009. Does state control affect managerial incentives? Evidence from China's publicly listed firms, Journal of Business Economics and Management 10(4): 291-311. http://dx.doi.org/10.3846/1611-1699.2009.10.291-311

Love, J. H.; Roper, S.; Du, J. 2009. Innovation, ownership and profitability, International Journal of Industrial Organization 27(3): 424-434. http://dx.doi.org/10.1016/j.ijindorg.2008.11.001

Majumdar, K. 1995. Public, joint and private sectors in Indian industry: evaluating relative performance differences, Economic and Political Weekly 30(7-8): M25-32.

Malerba, F.; Orsenigo, L.; Peretto, P. 1997. Persistence of innovative activities, sectoral patterns of innovation and international specialization, International Journal of Industrial Organization 15(6): 801-826. http://dx.doi.org/10.1016/S0167-7187(97)00012-X

Mathews, J. H. 1992. Bounded population growth: a curve fitting lesson, Mathematics and Computer Education 26(2): 169-176.

Molas-Gallart, J.; Tang, P. 2006. Ownership matters: Intellectual property, privatization and innovation, Research Policy 35(2): 200-212. http://dx.doi.org/10.1016/j.respol.2005.03.017

Moreno, J. J.; Castillo, L. L. 2011. Corporate growth, age and ownership structure: empirical evidence in Spanish firms, Journal of Business Economics and Management 12(1): 164-196. http://dx.doi.org/10.3846/16111699.2011.555449

Nelson, R. R. 2005. Technology, Institutions, and Economic Growth. USA: Harvard University Press.

Nelson, R. R. (Ed.). 1993. National Innovation Systems: a Comparative Analysis. New York: Oxford University Press.

Nolan, P.; Xiaoqiang, W. 1999. Beyond privatization: institutional innovation and growth in China's large state-owned enterprises, World Development 27(1): 169-200.

http://dx.doi.org/10.1016/S0305-750X(98)00132-6

North, D. C. 1990. Institutions, Institutional Change and Economic Performance. Cambridge, UK: Cambridge University Press.

Park, G.; Park, Y. 2006. On the measurement of patent stock as knowledge indicators, Technological Forecasting and Social Change 73(7): 793-812. http://dx.doi.org/10.1016/j.techfore.2005.09.006

Parkes, A.; Schankerman, M. 1984. The rate of obsolescence of patents, research gestation lags, and the private rate of return to research resources, in Griliches, Z. (Ed.). RङD, Patents and Productivity. Chicago: Chicago University Press, 73-88.

Rasiah, R. 1995. Foreign Capital and Industrialization in Malaysia. London: St. Martin London. http://dx.doi.org/10.1057/9780230377585 
Rasiah, R. 2001. Pre-crisis economic weaknesses and vulnerabilities, in Jomo, K. S. (Ed.). Malaysian Eclipse: Economic Crisis and Recovery. London: Zed Books, 47-66.

Rasiah, R. 2002. Manufactured exports, employment, skills and wages in Malaysia, Employment Paper. Switzerland: International Labor Office.

Reinert, E. S. 2008. How Rich Countries Got Rich and Why Poor Countries Stay Poor. London: Constable.

Rogers, E. M. 1995. Diffusion of Innovations. $4^{\text {th }}$ edition. New York: The Free Press.

Romer, D. 1996. Advanced Macroeconomics. New York: McGraw Hill.

Shleifer, A. 1998. State versus private ownership, Journal of Economic Perspectives 14: 133-150. http://dx.doi.org/10.1257/jep.12.4.133

Tarasyev, A.; Watanabe, C. 1999. Optimal Control of R\&D Investment in a Techno-metabolic System. Laxenburg: Interim Report for the International Institute for Applied System Analysis.

Twiss, B. C. 1992. Forecasting for Technologists and Engineers: A Practical Guide for Better Decisions. London: IEE Management of Technology Series (15).

Wad, P.; Chandran, V. G. R. 2011. Automotive industry in Malaysia: an assessment of its development, International Journal of Automotive Technology and Management 11(2): 152-171. http://dx.doi.org/10.1504/IJATM.2011.039542

Watanabe, C.; Hur, J. Y.; Lei, S. 2006. Converging trend of innovation efforts in high technology firms under paradigm shift: a case of Japan's electrical machinery, Omega 34(2): 178-188. http://dx.doi.org/10.1016/j.omega.2004.09.002

Watanabe, C.; Asgari, B.; Nagamatsu, A. 2003. Virtuous cycle between R\&D, functionality development and assimilation capacity for competitive strategy in Japan's high-technology industry, Technovation 23(11): 879-900. http://dx.doi.org/10.1016/S0166-4972(02)00041-X

Watanabe, C.; Asgari, B.; Zhu, B. 2002. Comparative Analysis of Institutional Elasticity on the Effect of Energy Technology Policy: Comparison of Diffusion Trajectory of PV Technology in Japan, the USA and Europe, Paper Presented at the $5^{\text {th }}$ Annual Conference on Global Economic Analysis. Taipei, 5-7 June.

Wong, C.-Y.; Goh, K.-L. 2010a. Modeling the behaviour of science and technology: self-propagating growth in the diffusion process, Scientometrics 84(3): 669-686. http://dx.doi.org/10.1007/s11192-010-0220-x

Wong, C.-Y.; Goh, K.-L. 2010b. Growth behavior of publications and patents: a comparative study on selected Asian economies, Journal of Informetrics 4(4): 460-474.

http://dx.doi.org/10.1016/j.joi.2010.04.002

Wong, C.-Y.; Thirucelvam, K.; Kurunathan, R. 2010. Diffusion trajectories of emerging sciences in Malaysian R\&D system, Technological Forecasting and Social Change 77(7): 1109-1125. http://dx.doi.org/10.1016/j.techfore.2010.02.008

Zheng, J.; Liu, X.; Bigsten, A. 2003. Efficiency, technical progress, and best practice in Chinese state enterprises (1980-1994), Journal of Comparative Economics 31(1): 134-152. http://dx.doi.org/10.1016/S0147-5967(02)00010-0

Zhu, B.; Asgari, B.; Watanabe, C. 2002. Comparative Analysis of Institutional Elasticity on the Effect of Energy Technology Policy: Comparison of Diffusion Trajectory of PV Technology in Japan, the USA and Europe, Paper presented at the $5^{\text {th }}$ Annual Conference on Global Economic Analysis. Taipei, June 5-7.

Chan-Yuan WONG is presently a lecturer at the department of Science and Technology Studies, University of Malaya. He has obtained his Ph.D. in Applied Statistics at the University of Malaya, Malaysia. $\mathrm{He}$ is also researcher for Malaysian Industry-Government Group for High Technology (MIGHT) in several research projects, and IDRC-sponsored projects on Innovation in Asian Megacities and Policies for Innovation Financing in Asia. Chan-Yuan graduated from Deakin University with a Bachelor degree in Robotics Engineering and received his Master degree in Systems Engineering and Management from Malaysia University of Science and Technology (a collaborative program with the Massachusetts 
Institute of Technology). He has his articles published in several international journals on mathematical analysis of growth and diffusion and Malaysia's system of innovation, including Scientometrics, Journal of Informetrics, Technological Forecasting and Social Change, World Patent Information, Asian Journal of Technological Innovation, and Malaysian Journal of Science and Technology Studies.

V. G. R. Chandran GOVINDARAJU teaches at the University of Malaya. He holds a Ph.D. in Economics. His area of interest is international trade, development economics, innovation economics and industrial organization, especially in developing countries. His works have been published in Journal of Policy Modeling, Energy Policy, Applied Economics Letters, International Journal of Innovation and Technology Management, Asian-African Journal of Economics and Econometrics and several other academic journals. He has also served as a consultant/research associate to various organizations including United Nations Industrial Development Organization (UNIDO), United Nations, Kuala Lumpur, Copenhagen Business School, Denmark, Malaysian Industry-Government Group for High Technology (MIGHT), and Ministry of Science, Technology and Innovation. 